\title{
Meta-analysis of randomized controlled trials on the efficacy of thoracic epidural anesthesia in preventing atrial fibrillation after coronary artery bypass grafting
}

Wan-Jie Gu ${ }^{1,2}$, Chun-Yin Wei ${ }^{1}$, De-Qing Huang ${ }^{3}$ and Rui-Xing Yin ${ }^{1 *}$

\begin{abstract}
Background: Postoperative atrial fibrillation (POAF) is one of the most common complications in patients undergoing coronary artery bypass grafting (CABG). The goal of this meta-analysis was to evaluate the efficacy of thoracic epidural anesthesia (TEA) in preventing POAF in adult patients undergoing CABG.

Methods: MEDLINE and EMBASE were searched to identify randomized controlled trails in adult patients undergoing $C A B G$ who were randomly assigned to receive general anesthesia plus thoracic epidural anesthesia (GA + TEA) or general anesthesia only (GA). Two authors independently extracted data using a standardized Excel file. The primary outcome measure was the incidence of POAF. We used DerSimonian-Laird random-effects models to compute summary risk ratios with $95 \%$ confidence intervals.

Results: Five studies involving 540 patients met our inclusion criteria. No significant difference in the incidence of POAF was observed between the two groups (risk ratio, $0.61 ; 95 \%$ confidence interval, 0.33 to $1.12 ; P=0.11$ ), with significant heterogeneity among the studies $\left(I^{2}=73 \%, P=0.005\right)$. Sensitivity analyses by primary endpoint, methodological quality and surgical technique yielded similar results.

Conclusions: The limited evidence suggests that TEA shows no beneficial efficacy in preventing POAF in adult patients undergoing CABG. However, the results of this meta-analysis should be interpreted with caution due to significant heterogeneity of the studies included. Thus, the potential infuence of TEA on the incidence of atrial fibrillation following CABG warrants further investigation.
\end{abstract}

Keywords: Thoracic epidural anesthesia, Postoperative atrial fibrillation, Meta-analysis

\section{Background}

Postoperative atrial fibrillation (POAF) is one of the most common complications encountered after CABG. The incidence of POAF reported in previous studies varies between $20 \%$ and $40 \%$, depending on definitions and methods of detection [1-3]. Although the majority of POAF are benign and self-limiting, it has been shown to increase both the length of hospital stay and total hospital costs significantly $[4,5]$. Thus, the prevention of

\footnotetext{
* Correspondence: yinruixing@yahoo.com.cn

'Department of Cardiology, Institute of Cardiovascular Diseases, the First Affiliated Hospital, Guangxi Medical University, Nanning, Guangxi, People's Republic of China

Full list of author information is available at the end of the article
}

POAF is of great importance. In recent decades, many pharmacologic interventions have been used to prevent the development of POAF, for example, $\beta$-blockers, sotalol, amiodarone, and magnesium [6]. However, all of them have limited effectiveness and are not free of side effects. The limited efficacies of pharmacologic interventions have stimulated research into alternative prophylactic strategies to prevent POAF.

The etiology of POAF is not widely known and has been related to many risk factors [7]. Increased sympathetic activation appears to be important in the pathogenesis of POAF [8]. As TEA reduces sympathetic activity, it seems to be a promising non-pharmacologic intervention to reduce the incidence of POAF and could

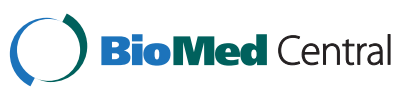


be beneficial in patients at increased risk of perioperative arrhythmias [9]. However, the studies regarding TEA in preventing POAF conveyed mixed and inconclusive results [10-19]. We therefore performed a meta-analysis based on relevant randomized controlled trials to evaluate the efficacy of TEA in preventing POAF in adult patients undergoing CABG.

\section{Methods}

\section{Literature search and selection criteria}

MEDLINE and EMBASE (up to March 1, 2012) were searched for randomized controlled trails in adult patients undergoing CABG who were randomly assigned to receive GA + TEA or GA only. Search terms included "thoracic epidural" and "coronary artery". No language restriction was imposed. The searches were limited to human subjects and randomized controlled trials. In addition, reference lists from the identified articles were manually examined for relevant new articles. This process was performed iteratively until no additional articles could be identified.

We included studies in all languages irrespective of blinding when the following inclusion criteria were met: enrolled adult patients (i.e., $18 \mathrm{yr}$ or older) undergoing CABG; randomly assigned to receive GA + TEA or GA only; reported data on the incidence of POAF; and provided definition and monitoring of POAF. Tials were excluded if they enrolled patients 1) requiring salvage CABG, 2) undergoing CABG and valve surgery at the same time, 3) existing preoperative atrial fibrillation.

\section{Data extraction and quality assessment}

Two authors (WJG and CYW) independently extracted data from all eligible studies using a standardized Excel file. The following data were extracted from each study: first author's last name, year of publication, number of enrolled patients, surgery type, CABG technique, perioperative management of TEA, the definition and monitoring methods of POAF, and outcome data. Any disagreements were resolved by discussion and consensus.

We assessed the methodological quality of included RCTs using the Jadad scale [20]. The scale consists of three items describing randomization ( $0-2$ points), blinding ( $0-2$ points), and dropouts and withdrawals $(0-1$ points) in the report of a randomized controlled trial. A score of 1 is given for each of the points described. A further point is obtained where the method of randomization and/or blinding is given and is appropriate; whereas it is inappropriate a point is deducted. Higher scores indicate better reporting. The quality scale ranges from 0 to 5 points. The studies are said to be of low quality if the Jadad score is $\leq 2$ and high quality if the score is $\geq 3$ [21].

\section{Statistical analysis}

We assessed the overall efficacy of TEA in preventing POAF based on the data from included 5 RCTs. The incidence of POAF was treated as dichotomous variables and was expressed as risk ratio (RR) with 95\% confidence interval (CI) for each study.

Heterogeneity across studies was tested by using the $\mathrm{I}^{2}$ statistic, which is a quantitative measure of inconsistency across studies. Studies with an $\mathrm{I}^{2}$ statistic of $25 \%$ to $50 \%$ are considered to have low heterogeneity, those with an $\mathrm{I}^{2}$ statistic of $50 \%$ to $75 \%$ are considered to have moderate heterogeneity, and those with an $\mathrm{I}^{2}$ statistic of $>75 \%$ are considered to have a high degree of heterogeneity [22]. $\mathrm{I}^{2}$ less than $50 \%$ has been considered as nonimportant heterogeneity [23]. In case of important heterogeneity, we used the random-effects model. We further conducted sensitivity analyses to assess the robustness of our results and to explore the potential sources of heterogeneity. Sensitivity analyses were done according to the following: (1) primary endpoint; (2) methodological quality; and (3) CABG technique.

Potential publication bias was evaluated by inspecting funnel plots and performing Begg and Egger tests [24,25]. A two-tailed $P$-value of less than 0.05 was judged as statistically significant. All statistical analyses were performed using Review Manager, Version 5.0 (The Nordic Cochrane Centre, The Cochrane Collaboration; Copenhagen, Denmark).

\section{Results}

\section{Identification of eligible studies}

A total of 97 studies were identified by the initial database search. Thirty-five studies were excluded because of duplicate studies and 20 studies were excluded based on the titles and abstracts. After detailed assessment, 32 studies were excluded because they did not meet our inclusion criteria. For the remaining $10 \mathrm{RCTs}$, five of these were also excluded because POAF was not well defined and the monitoring of POAF was not specified clearly [10-14]. Finally, five RCTs that met our inclusion criteria were included in the present meta-analysis [15-19]. The flowchart of studies included in meta-analysis was shown in Figure 1.

\section{Study characteristics}

The summary of RCTs included in the meta-analysis is shown in Table 1 . These studies were published between 2001 and 2009. The size of the RCT ranged from 50 to 163 (total 540). Three studies in this meta-analysis enrolled patients undergoing CABG with $\mathrm{CPB}$ technique $[15,16,18]$, the remaining two studies included patients undergoing $\mathrm{CABG}$ with $\mathrm{OPCAB}$ technique $[17,19]$. The quality of the included studies was assessed by the Jadad 


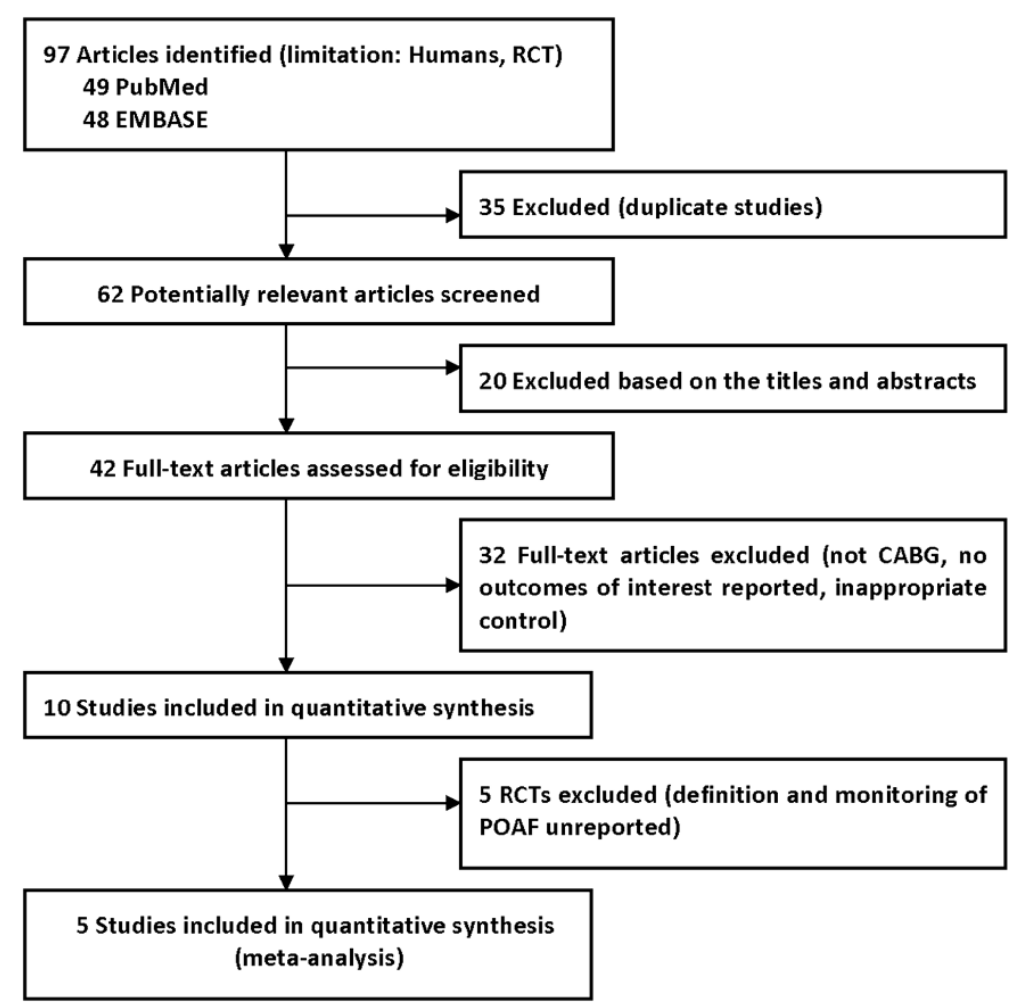

Figure 1 Selection Process for RCTs Included in the Meta-analysis. CABG, coronary artery bypass grafting; POAF, postoperative atrial fibrillation; RCT, randomized controlled trials.

score. The median Jadad score of the studies included was 3 (range from 2 to 3 ).

\section{TEA and POAF}

The definition and monitoring of POAF in the various studies are summarized in Table 2. Overall, 540 patients were included in this analysis (247 in the TEA + GA group and 293 in the GA only group). Meta-analysis of 5 studies using a random-effects model suggested that TEA had no significant effect on the prevention of POAF (RR 0.61, 95\% CI 0.33 to 1.12; $P=0.11$; Figure 2). There was significant heterogeneity among the studies $\left(\mathrm{I}^{2}=73 \%, P=0.005\right.$; Figure 2).

\section{Sensitivity analyses}

Subsequently, we performed sensitivity analyses to explore the source of this heterogeneity and to examine the influence of various exclusion criteria on the combined estimates. Exclusion of 2 studies in which POAF did not served as the primary endpoint yielded similar results (RR $0.64,95 \%$ CI 0.26 to $1.58 ; P=0.33$ ), with substantial evidence of heterogeneity $\left(\mathrm{I}^{2}=82 \%, P=0.004\right)$ $[18,19]$. After exclusion of 2 studies with low-quality studies (Jadad score $\leq 2$ ), the results were still maintained (RR $0.73,95 \%$ CI 0.37 to $1.44 ; P=0.36$ ), yet heterogeneity was still present $\left(\mathrm{I}^{2}=68 \%, P=0.04\right) \quad[15,17]$.
Exclusion of 2 studies that conducted in patients undergoing $C A B G$ with $O P C A B$ technique did not change the pooled results (RR $0.98,95 \%$ CI 0.72 to $1.35 ; P=0.92$ ), but no evidence of heterogeneity was observed among the remaining studies $\left(\mathrm{I}^{2}=0 \%, P=0.44\right)[17,19]$.

\section{Publication bias}

Publication bias was not assessed because of the limited number (below 10) of studies included in each analysis.

\section{Discussion}

In the present meta-analysis, we have reviewed the literature regarding the efficacy of TEA in preventing POAF in adult patients undergoing CABG. The pooled results from meta-analysis of five RCTs using a randomeffects model suggest that TEA shows no beneficial efficacy in preventing POAF in adult patients undergoing CABG. Also, substantial heterogeneity across the studies was observed.

The main finding of our meta-analysis seems to contradict a previous review on the topic, which assessed the effects of TEA on the clinical outcomes in patients undergoing cardiac surgery. In detail, in a meta-analysis by Svircevic et al. [26], it was noted that "the use of TEA in patients undergoing cardiac surgery reduces the risk of postoperative supraventricular arrhythmias." In fact, 
Table 1 Summary of RCTs included in the meta-analysis

\begin{tabular}{|c|c|c|c|c|c|c|c|c|c|c|}
\hline \multirow{2}{*}{$\begin{array}{l}\text { First author/Year of } \\
\text { publication }\end{array}$} & \multirow{2}{*}{$\begin{array}{l}\text { No. of } \\
\text { subjects }\end{array}$} & \multirow{2}{*}{$\begin{array}{l}\text { Surgery } \\
\text { type }\end{array}$} & \multirow{2}{*}{$\begin{array}{l}\text { CABG } \\
\text { technology }\end{array}$} & \multirow{2}{*}{$\begin{array}{l}\text { TEA continued } \\
\text { postoperatively }\end{array}$} & \multirow[t]{2}{*}{ TEA } & \multirow[t]{2}{*}{ Perioperative management of TEA } & \multirow{2}{*}{$\begin{array}{l}\text { Primary } \\
\text { endpoint? }\end{array}$} & \multicolumn{2}{|l|}{ POAF } & \multirow{2}{*}{$\begin{array}{l}\text { Study } \\
\text { design/ } \\
\text { Jadad } \\
\text { score }\end{array}$} \\
\hline & & & & & & & & $\mathrm{TEA}+\mathrm{GA}$ & GA & \\
\hline Jidéus/2001 [15] & 121 & elective CABG & $\mathrm{CPB}$ & Unclear & $\begin{array}{l}\text { T2-T5, the day } \\
\text { before surgery }\end{array}$ & $\begin{array}{l}\text { Intraoperative: bupivacaine } 5 \mathrm{mg} / \mathrm{mL} \text {, } \\
\text { with an infusion rate of } 4 \text { to } 8 \mathrm{~mL} / \mathrm{h} \text {. } \\
\text { Postoperative: continuous infusion of } \\
\text { bupivacaine }(2 \mathrm{mg} / \mathrm{mL} \text { ) and sufentanil } \\
\text { (1 mg/mL) epidurally ( } 3 \text { to } 7 \mathrm{~mL} / \mathrm{h} \text { ) }\end{array}$ & Yes & $13 / 41$ & $29 / 80$ & $\mathrm{RCT} / 2$ \\
\hline Nygard/2004 [16] & 163 & elective CABG & CPB & 4 days & $\begin{array}{l}\text { T1-T3, the day } \\
\text { before surgery }\end{array}$ & $\begin{array}{l}\text { Intraoperative and postoperative : } \\
\text { bolus doses of } 4 \mathrm{~mL} \text { of bupivacaine, } \\
5 \mathrm{mg} / \mathrm{mL} \text {, given hourly }\end{array}$ & Yes & 28/79 & $25 / 84$ & $\mathrm{RCT} / 3$ \\
\hline Bakhtiary/2007 [17] & 132 & elective CABG & OPCAB & 3 days & $\begin{array}{l}\mathrm{T} 1-\mathrm{T} 3 \text {, the day } \\
\text { before surgery }\end{array}$ & $\begin{array}{l}\text { Preoperative and postoperative: } \\
\text { continuous infusion with ropivacaine } \\
0.16 \% \text { and sufentanil } 1 \mathrm{~g} / \mathrm{mL} \text { at an } \\
\text { hourly rate of } 2 \text { to } 5 \mathrm{~mL} \text { was started } \\
\text { after a bolus dose of } 6 \mathrm{~mL}\end{array}$ & Yes & $2 / 66$ & $18 / 66$ & $\mathrm{RCT} / 2$ \\
\hline Tenenbein/2008 [18] & 50 & $\begin{array}{l}\text { elective or } \\
\text { semi-elective } \\
\text { CABG }\end{array}$ & CPB & 2 days & $\begin{array}{l}\text { T2-T5, at least } \\
\text { four hours prior } \\
\text { to systemic } \\
\text { heparinization }\end{array}$ & $\begin{array}{l}\text { Intraoperative: } 5 \text {-mL bolus of } 0.75 \% \\
\text { ropivacaine and } 200 \mu \mathrm{g} \text { of hydromorphone } \\
\text { in the epidural catheter, followed by } \\
\text { infusion of } 0.75 \% \text { ropivacaine at } 5 \mathrm{~mL} / \mathrm{h} \text {. } \\
\text { Postoperative: continuous infusion lasting } \\
48 \mathrm{~h} \text { and consisting of } 0.2 \% \text { ropivacaine, } \\
\text { with } 15 \mu \mathrm{g} / \mathrm{mL} \text { of hydromorphone titrated. }\end{array}$ & No & $6 / 25$ & $9 / 25$ & $\mathrm{RCT} / 3$ \\
\hline Caputo/2009 [19] & 74 & elective CABG & OPCAB & 3 days & $\begin{array}{l}\text { T2-T4, before } \\
\text { induction of } \\
\text { anesthesia }\end{array}$ & $\begin{array}{l}\text { Intraoperative and postoperative: continuous } \\
\text { infusion of } 0.125 \% \text { bupivacaine and } \\
0.0003 \% \text { clonidine ( } 150 \mathrm{~g} \text { in } 500 \mathrm{~mL}) \text { at an } \\
\text { initial rate of } 10 \mathrm{~mL} / \mathrm{h}\end{array}$ & No & $7 / 36$ & $18 / 38$ & $\mathrm{RCT} / 3$ \\
\hline
\end{tabular}


Table 2 Definition and monitoring of POAF used in the included trials of the meta-analysis

\begin{tabular}{lll}
\hline First author/Year of publication & Definition of POAF & Monitoring of POAF \\
\hline Jideus/2001 [15] & $\begin{array}{l}\text { The absence of consistent P waves before each QRS } \\
\text { complex and with an irregular ventricular rate, } \\
\text { lasting } 30 \text { seconds or longer }\end{array}$ & $\begin{array}{l}\text { Twenty-four hour Holter ECG performed on the } \\
\text { first } 4 \text { consecutive days, or until clinically } \\
\text { documented sustained atrial fibrillation }\end{array}$ \\
Nygard/2004 [16] & $\begin{array}{l}\text { New-onset atrial fibrillation (irrespective of treatment), } \\
\text { an irregular narrow complex rhythm with absence } \\
\text { of P waves }\end{array}$ & $\begin{array}{l}\text { Twenty-four hour Holter ECG performed on the } \\
\text { first } 5 \text { consecutive days }\end{array}$ \\
Bakhtiary/2007 [17] & $\begin{array}{l}\text { An episode of atrial fibrillation or flutter lasting for } \\
\text { more than } 30 \text { seconds }\end{array}$ & $\begin{array}{l}\text { Continuous ECG performed for 48 hours, then, } \\
\text { twice daily 12-lead ECG performed until } \\
\text { hospital discharge }\end{array}$ \\
Tenenbein/2008 [18] & A need for pharmacologic treatment & $\begin{array}{l}\text { Holter ECG performed on the first three } \\
\text { postoperative days } \\
\text { Caputo/2009 [19] }\end{array}$ \\
& New onset of atrial fibrillation not present preoperatively & $\begin{array}{l}\text { Continuous ECG performed in the intensive care } \\
\text { unit, high-dependency unit, and ward, and daily } \\
\text { 12-lead ECG analysis }\end{array}$ \\
\hline
\end{tabular}

POAF, postoperative atrial fibrillation; ECG, electrocardiogram.

the contribution may not be conclusive. As their authors clearly emphasized, the included studies were heterogeneous and the study by Scott et al. [27] in 420 patients mainly contributed to this result. In this study, all patients discontinued $\beta$-blockers therapy during the study period. Moreover, the patients in TEA + GA group received clonidine, while the patients in GA group were not given this cardioprotective drug [28]. The above factors may result in the beneficial efficacy of TEA on supraventricular arrhythmias.

For the current meta-analysis, we evaluated the efficacy of TEA in preventing POAF in adult patients undergoing $\mathrm{CABG}$. In an attempt to produce robust results, we pre-stated rigorous inclusion criteria and included only RCTs that provided definition and monitoring of POAF. We found that there was no significant difference in the incidence of POAF between the two groups, but significant heterogeneity was observed among these studies. Our sensitivity analyses suggest that 2 studies conducted in patients undergoing CABG with $\mathrm{OPCAB}$ technique probably contributed to the heterogeneity $[17,19]$. In addition, sensitivity analyses based other various exclusion criteria did not materially alter the pooled results, which added robustness to our main finding.
Our study provides additional interesting clues that may be useful for future research on the topic. Two RCTs included in our meta-analysis were conducted in patients undergoing $C A B G$ with $O P C A B$ technique instead of $\mathrm{CPB}[17,19]$. These two studies consistently suggest that TEA + GA significantly reduced the incidence of POAF. Thus, a new question arise, does TEA really reduce the incidence of POAF in patients undergoing CABG with OPCAB technique? However, a recent meta-analysis indicated that $\mathrm{OPCAB}$ technique was associated with lower incidence of POAF when compared with $\mathrm{CPB}$ technique in the population undergoing CABG [29]. Besides, in one study [17], the patients in the TEA group received ropivacaine which has a substantial anti-inflammatory effect [30]. In the other study [19], the epidural infusion protocol used was similar to the one used by Scott and colleagues [27] and clonidine was administered only to the patients in TEA group. These may make the isolated effects of TEA on the incidence of POAF become less clear and raise additional concerns on the interpretation of the positive results.

One could expect that use of TEA may cause potential complications in patients undergoing CABG. TEA may give rise to the following possible hazardous complications, such as the appearance of epidural hematoma.

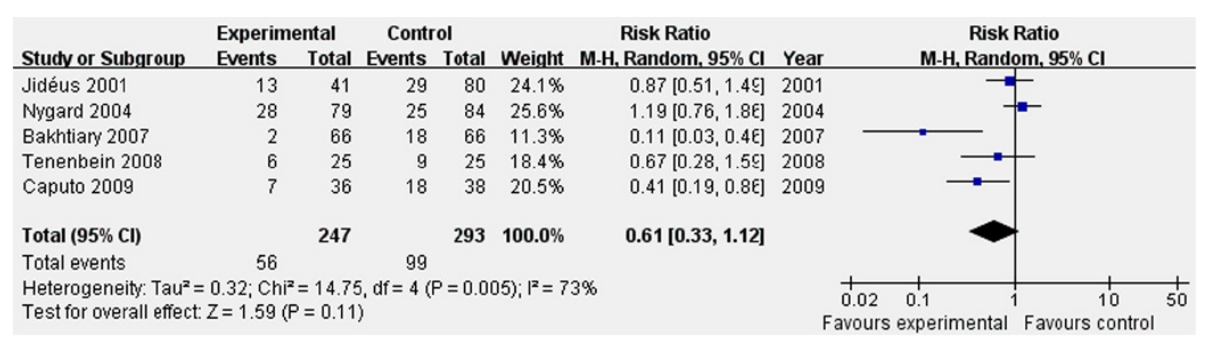

Figure 2 Forest plot for the incidence of POAF. There were no significant effects in preventing POAF as determined by the randomeffects model. $\mathrm{RR}$, relative risk; $\mathrm{Cl}$, confidence interval. 
Systematic anticoagulation needed during cardiopulmonary bypass could increase the incidence of epidural hematoma related to the use of an epidural catheter [31]. In addition, the intense sympathycolysis may lead to systemic hypotension, which can be difficult to correct. In the included studies, no cases of epidural hematoma were reported because this devastating complication is too rare to evaluate in randomized studies. Additional studies or data regarding the potential complications related to TEA are warranted.

There are several potential limitations that should be taken into account. First, substantial heterogeneity among studies was observed. Nevertheless, we were able to detect the major source of heterogeneity through the sensitivity analyses. Second, our analysis was based on only five RCTs and all of them were carried out in only western countries and just enrolled older age patients undergoing elective surgery. Thus, the results of the RCTs need to be reproduced in other populations. Morever, we only included the trial providing definition and monitoring of POAF. Because the end-point of our study was less POAF, the monitoring needs to specificied clearly for the various studies. Since identification of POAF is critical to the conclusion, the monitoring has to be standardized or at least specified. Otherwise the conclusions are hard to justify. Exclusion of the studies lacking a clear definition of POAF may have potential influence on the final analysis. Finally, these studies lack homogeneity in both the method of postoperative monitoring and in their definition of POAF. This may lead to potential underestimation and/or overestimation of the true incidence of POAF.

\section{Conclusion}

In summary, the limited evidence suggests that TEA shows no beneficial efficacy in preventing POAF in adult patients undergoing CABG. However, the results of this meta-analysis should be interpreted with caution due to significant heterogeneity of the studies included. Thus, the potential infuence of TEA on the incidence of atrial fibrillation following CABG warrants further investigation.

\section{Abbreviations \\ CABG: Coronary Artery Bypass Grafting; Cl: Confidence Interval; CPB: Cardiopulmonary Bypass; ECG: Electrocardiogram; GA: General Anesthesia; OPCAB: Off-Pump Coronary Artery Bypass; POAF: Postoperative Atrial Fibrillation; RCT: Randomized Controlled Trials; RR: Risk Ratio; TEA: Thoracic Epidural Anesthesia.}

\section{Competing interests}

The authors declare that they have no competing interests.

\section{Authors' contributions}

WJG conceived the study, participated in the design, collected the data, and drafted the manuscript. CYW collected the data, and performed statistical analyses. DQH helped to collect the data. RXY conceived the study, participated in the design, and helped to draft the manuscript. All authors read and approved the final manuscript.

\section{Acknowledgments}

This study was supported by the Science Foundation of Guangxi Returned Oversea Scholars (No: 0991004).

\section{Author details}

${ }^{1}$ Department of Cardiology, Institute of Cardiovascular Diseases, the First Affiliated Hospital, Guangxi Medical University, Nanning, Guangxi, People's Republic of China. ${ }^{2}$ Department of Anaesthesiology, the First Affiliated Hospital, Guangxi Medical University, Nanning, Guangxi, People's Republic of China. ${ }^{3}$ Department of Encephalopathy, the First Affiliated Hospital, Guangxi Traditional Chinese Medical University, Nanning, Guangxi, People's Republic of China.

Received: 2 April 2012 Accepted: 14 August 2012

Published: 19 August 2012

\section{References}

1. Mathew JP, Parks R, Savino JS, Friedman AS, Koch C, Mangano DT, Browner WS: Atrial fibrillation following coronary artery bypass graft surgery: predictors, outcomes, and resource utilization. MultiCenter Study of Perioperative Ischemia Research Group. JAMA 1996, 276:300-306.

2. Frost $L$, Mølgaard $H$, Christiansen EH, Jacobsen CJ, Pilegaard H, Thomsen PE: Atrial ectopic activity and atrial fibrillation/flutter after coronary artery bypass surgery. A case-base study controlling for confounding from age, beta-blocker treatment, and time distance from operation. Int J Cardiol 1995, 50:153-162.

3. Zaman AG, Archbold RA, Helft G, Paul EA, Curzen NP, Mills PG: Atrial fibrillation after coronary artery bypass surgery: a model for preoperative risk stratification. Circulation 2000, 101:1403-1408.

4. Mauldin PD, Weintraub WS, Becker ER: Predicting hospital costs for firsttime coronary artery bypass grafting from preoperative and postoperative variables. Am J Cardiol 1994, 74:772-775.

5. Aranki SF, Shaw DP, Adams DH, Rizzo RJ, Couper GS, VanderVliet M, Collins J J Jr, Cohn LH, Burstin HR: Predictors of atrial fibrillation after coronary artery surgery. Current trends and impact on hospital resources. Circulation 1996, 94:390-397.

6. Burgess DC, Kilborn MJ, Keech AC: Interventions for prevention of postoperative atrial fibrillation and its complications after cardiac surgery: a meta-analysis. Eur Heart J 2006, 27:2846-2857

7. Echahidi N, Pibarot P, O'Hara G, Mathieu P: Mechanisms, prevention, and treatment of atrial fibrillation after cardiac surgery. J Am Coll Cardio/ 2008, 51:793-801.

8. Kalman JM, Munawar M, Howes LG, Louis WJ, Buxton BF, Gutteridge G, Tonkin AM: Atrial fibrillation after coronary artery bypass grafting is associated with sympathetic activation. Ann Thorac Surg 1995, 60:1709-1715.

9. Scott NB, Turfrey DJ, Ray DA, Nzewi O, Sutcliffe NP, Lal AB, Norrie J, Nagels WJ, Ramayya GP: A prospective randomized study of the potential benefits of thoracic epidural anesthesia and analgesia in patients undergoing coronary artery bypass grafting. Anesth Analg 2001, 93:528-535.

10. Priestley MC, Cope L, Halliwell R, Gibson P, Chard RB, Skinner M, Klineberg PL Thoracic epidural anesthesia for cardiac surgery: the effects on tracheal intubation time and length of hospital stay. Anesth Analg 2002, 94:275-282.

11. Fillinger MP, Yeager MP, Dodds TM, Fillinger MF, Whalen PK, Glass DD: Epidural anesthesia and analgesia: effects on recovery from cardiac surgery. J Cardiothorac Vasc Anesth 2002, 16:15-20.

12. de Vries AJ, Mariani MA, van der Maaten JM, Loef BG, Lip H: To ventilate or not after minimally invasive direct coronary artery bypass surgery: the role of epidural anesthesia. J Cardiothorac Vasc Anesth 2002, 16:21-26.

13. Royse C, Royse A, Soeding P, Blake D, Pang J: Prospective randomized trial of high thoracic epidural analgesia for coronary artery bypass surgery. Ann Thorac Surg 2003, 75:93-100.

14. Barrington MJ, Kluger R, Watson R, Scott DA, Harris KJ: Epidural anesthesia for coronary artery bypass surgery compared with general anesthesia alone does not reduce biochemical markers of myocardial damage. Anesth Analg 2005, 100:921-928.

15. Jidéus $L$, Joachimsson $P O$, Stridsberg $M$, Ericson M, Tydén $H$, Nilsson L Blomström P, Blomström-Lundqvist C: Thoracic epidural anesthesia does 
not influence the occurrence of postoperative sustained atrial fibrillation. Ann Thorac Surg 2001, 72:65-71.

16. Nygård E, Sørensen LH, Hviid LB, Pedersen FM, Ravn J, Thomassen L, Svendsen JH, Eliasen K, Krogsgaard K, Aldershvile J: Effects of amiodarone and thoracic epidural analgesia on atrial fibrillation after coronary artery bypass grafting. J Cardiothorac Vasc Anesth 2004, 18:709-714.

17. Bakhtiary F, Therapidis $P$, Dzemali $O, A k K$, Ackermann $H$, Meininger $D$, Kessler P, Kleine P, Moritz A, Aybek T, Dogan S: Impact of high thoracic epidural anesthesia on incidence of perioperative atrial fibrillation in offpump coronary bypass grafting: a prospective randomized study. J Thorac Cardiovasc Surg 2007, 134:460-464.

18. Tenenbein PK, Debrouwere R, Maguire D, Duke PC, Muirhead B, Enns J, Meyers M, Wolfe K, Kowalski SE: Thoracic epidural analgesia improves pulmonary function in patients undergoing cardiac surgery. Can J Anaesth 2008, 55:344-350.

19. Caputo M, Alwair H, Rogers CA, Ginty M, Monk C, Tomkins S, Mokhtari A, Angelini GD: Myocardial, inflammatory, and stress responses in off-pump coronary artery bypass graft surgery with thoracic epidural anesthesia. Ann Thorac Surg 2009, 87:1119-1126.

20. Jadad AR, Moore RA, Carroll D, Jenkinson C, Reynolds DJ, Gavaghan DJ, McQuay HJ: Assessing the quality of reports of randomized clinical trials: is blinding necessary? Control Clin Trials 1996, 17:1-12.

21. Kjaergard LL, Villumsen J, Gluud C: Reported methodologic quality and discrepancies between large and small randomized trials in metaanalyses. Ann Intern Med 2001, 135:982-989.

22. Higgins JP, Thompson SG, Deeks JJ, Altman DG: Measuring inconsistency in meta-analyses. BMJ 2003, 327:557-560.

23. Armitage P, Berry G, Matthews JNS: Analysing Means and Proportions. Statistical Methods in Medical Research. Oxford: Blackwell Science; 2002:83-146.

24. Begg CB, Mazumdar M: Operating characteristics of a rank correlation test for publication bias. Biometrics 1994, 50:1088-1101.

25. Egger M, Davey Smith G, Schneider M, Minder C: Bias in meta-analysis detected by a simple, graphical test. BMJ 1997, 315:629-634.

26. Svircevic V, van Dijk D, Nierich AP, Passier MP, Kalkman CJ, van der Heijden GJ, Bax L: Meta-analysis of thoracic epidural anesthesia versus general anesthesia for cardiac surgery. Anesthesiology 2011, 114:271-282.

27. Scott NB, Turfrey DJ, Ray DA, Nzewi O, Sutcliffe NP, Lal AB, Norrie J, Nagels WJ, Ramayya GP: A prospective randomized study of the potential benefits of thoracic epidural anesthesia and analgesia in patients undergoing coronary artery bypass grafting. Anesth Analg 2001, 93:528-535.

28. Wijeysundera DN, Bender JS, Beattie WS: Alpha-2 adrenergic agonists for the prevention of cardiac complications among patients undergoing surgery. Cochrane Database Syst Rev 2009, 7:CD004126.

29. Panesar SS, Athanasiou T, Nair S, Rao C, Jones C, Nicolaou M, Darzi A: Early outcomes in the elderly: a meta-analysis of 4921 patients undergoing coronary artery bypass grafting-comparison between off-pump and onpump techniques. Heart 2006, 92:1808-1816.

30. Blumenthal S, Borgeat A, Pasch T, Reyes L, Booy C, Lambert M, Schimmer RC, Beck-Schimmer B: Ropivacaine decreases inflammation in experimental endotoxin-induced lung injury. Anesthesiology 2006, 104:961-969.

31. Ho AM, Chung DC, Joynt GM: Neuraxial blockade and hematoma in cardiac surgery: estimating the risk of a rare adverse event that has not (yet) occurred. Chest 2000, 117:551-555.

\section{doi:10.1186/1471-2261-12-67}

Cite this article as: Gu et al:: Meta-analysis of randomized controlled trials on the efficacy of thoracic epidural anesthesia in preventing atrial fibrillation after coronary artery bypass grafting. BMC Cardiovascular Disorders 2012 12:67.

\section{Submit your next manuscript to BioMed Central and take full advantage of:}

- Convenient online submission

- Thorough peer review

- No space constraints or color figure charges

- Immediate publication on acceptance

- Inclusion in PubMed, CAS, Scopus and Google Scholar

- Research which is freely available for redistribution 